Original Research Article

\title{
An evaluation of knowledge, attitude and practice of pharmacovigilance among prescribers in a teaching hospital of south India
}

\author{
Prasad R. Shivarudraiah ${ }^{1}$, Ravi H. Kudthni ${ }^{1 *}$, Santhosh Ramakrishna ${ }^{1}$, S. S. Koushik ${ }^{2}$, \\ Prajna V. Karki ${ }^{2}$, Radhika Kedia ${ }^{2}$
}

${ }^{1}$ Department of Pharmacology, ${ }^{2}$ MBBS Student, Shridevi Institute of Medical Sciences and Research Hospital, Tumkur, Karnataka, India

Received: 07 July 2017 Accepted: 29 July 2017

*Correspondence to:

Dr. Ravi H. Kudthni,

Email: docravidr@gmail.com

Copyright: () the author(s), publisher and licensee Medip Academy. This is an openaccess article distributed under the terms of the Creative Commons Attribution NonCommercial License, which permits unrestricted noncommercial use, distribution, and reproduction in any medium, provided the original work is properly cited.

\begin{abstract}
Background: Adverse drug reactions (ADRs) represent a serious health problem. Effective generation of ADR related data helps in practicing evidence-based medicine and thus prevents many adverse drug reactions. Spontaneous reporting of ADRs has remained the major sources of information of pharmacovigilance. Underreporting of ADRs is a common problem. In order to improve the reporting rate, it is important to improve the Knowledge, Attitude and Practices (KAP) of the prescribers regarding ADR reporting and Pharmacovigilance. Hence this study was undertaken to assess the knowledge, attitude and practice regarding Pharmacovigilance among doctors of Shridevi Institute of Medical Sciences and Research Hospital, Tumkur, Karnataka.

Methods: This was a cross sectional, observational, questionnaire based study conducted using a predesigned Knowledge Attitude Practice (KAP) questionnaire among 110 doctors. The completed KAP questionnaire was collected and data analyzed.
\end{abstract}

Results: Most of the doctors (98.15\%) accepted that reporting ADR is necessary. $67.31 \%$ agreed that ADR reporting is necessary for identifying safety of the drug and $94.44 \%$ agreed that pharmacovigilance should be taught in detail to healthcare professionals. But there was a huge gap between the ADR experienced $(80 \%)$, and ADR reported $(25.45 \%)$ by the prescribers. Only $29.09 \%$ medical professionals have ever seen the ADR reporting form and only $16.36 \%$ respondents have been trained on reporting on ADR.

Conclusions: Study revealed that the majority of the doctors had a good knowledge but poor attitude and practice of pharmacovigilance. They should be trained properly on ADR reporting to improve the current scenario in the pharmacovigilance program of the country.

Keywords: Adverse drug reaction, Attitude, Knowledge, Practices, Pharmacovigilance

\section{INTRODUCTION}

Pharmacological interventions are an integral part of the patient care system. The safety of the patients with regard to the cautious use of medicines is of highest priority in the modern day therapy. Adverse drug reactions (ADRs) are associated with significant morbidity and mortality in addition to imposing considerable economic burden on the society. Reducing the incidence and consequences associated with adverse drug reactions is a crucial challenge in drug use..$^{1-4}$

The safe use of medicine is an important aspect that affects each and every member of society. Reducing the incidence and consequences associated with adverse drug reactions is a crucial challenge in drug use.

The World Health Organization (WHO) defines an ADR as 'any response to a drug that is noxious and unintended, 
and that occurs at doses used in humans for prophylaxis, diagnosis, or therapy, excluding failure to accomplish the intended purpose'. 5

Effective generation of ADR related data helps in practicing evidence-based medicine and thus prevents many adverse drug reactions. Several countries have initiated Pharmacovigilance programs to monitor the drugs causing ADRs. ${ }^{6}$

According to World Health Organization (WHO) definition, Pharmacovigilance is, "The science and the activities which relate to the detection, assessment, understanding and the prevention of adverse effects or any other drug-related problems". 6

The Uppsala Monitoring Centre (UMC, WHO), Sweden, maintains the international database of the adverse drug reaction reports. It has been estimated that only $6-10 \%$ of all the ADRs are reported. ${ }^{7}$

Spontaneous reporting of ADRs has remained the cornerstone and major sources of information of pharmacovigilance and is important in maintaining patient safety. Underreporting of ADRs is a common problem and still remains a major obstacle in the complete success of Pharmacovigilance program. Spontaneous reporting of ADRs has played a major role in detection of unsuspected, serious, and unusual ADRs previously undetected during the clinical trial phases. This has led to the withdrawal of many drugs in recent past. ${ }^{8}$

The ultimate aim of pharmacovigilance is to ensure safe and rational use of medicines, once they are released for general use in the society. The most important outcome of pharmacovigilance is the prevention of negative consequences of pharmacotherapy.

Good pharmacovigilance programs will identify the risks and the risk factors in the shortest possible time so that harm can be avoided or minimized. Physicians, pharmacist and nurses are in a position to play a major key role in pharmacovigilance programme. Studies from different settings indicate inadequate knowledge about pharmacovigilance among healthcare professionals as well as attitudes that are associated with a high degree of underreporting. ${ }^{9}$

In order to improve the reporting rate, it is important to improve the Knowledge, Attitude and Practices (KAP) of the healthcare professionals regarding ADR reporting and Pharmacovigilance. Prior to carry out any intervention, it is necessary to evaluate the baseline KAP of the healthcare professionals regarding ADR monitoring and Pharmacovigilance. For improvement of the participation of health professionals in spontaneous reporting, it is necessary to design strategies that modify both the intrinsic (knowledge, attitude and practices) and extrinsic (relationship between health professionals and their patients, the health system and the regulators) factors. A knowledge, attitude, and practice (KAP) analysis may provide an insight into the intrinsic factors and help understand the reasons for under- reporting. ${ }^{10}$

Spontaneous reporting system is considered the main mechanism of pharmacovigilance study for gathering information about ADRs. Hence this study was undertaken to assess the knowledge, attitude and practice regarding Pharmacovigilance among doctors from all clinical departments of Shridevi Institute of Medical Sciences and Research Hospital, Tumkur, Karnataka, India.

\section{METHODS}

\section{Study setting}

This study was conducted at Shridevi Institute of Medical Sciences and Research Hospital, Tumkur, a tertiary care Hospital in Karnataka, India. The study was a crosssectional questionnaire based study.

\section{Study population}

The study participants consisted of doctors from all clinical departments of Shridevi Institute of Medical Sciences and Research Hospital.

\section{Questionnaire}

KAP (knowledge, attitudes and practices) questionnaire was designed to assess the knowledge of pharmacovigilance, attitudes towards pharmacovigilance, and their practice on ADR reporting. These questions were designed based on earlier studies for assessing KAP of ADR reporting. ${ }^{10-12}$ The questionnaire had 22 questions in all. Respondents were not required to mention their identity on the questionnaires.

The details of the questionnaire are as follows:

- Knowledge-related questions: The assessment of participant's knowledge of pharmacovigilance included ten questions (items) on definition and purpose of pharmacovigilance, responsibility of reporting ADRs, knowledge of National Pharmacovigilance Programme(NPP), and regulatory body responsible for monitoring ADRs.

- Attitude-related questions: The assessment of participant's attitudes toward pharmacovigilance included five questions (items) on the necessity of reporting ADRs, teaching of pharmacovigilance, prevention of $\mathrm{ADR}$, and opinion about $\mathrm{ADR}$ monitoring center.

- Practice-related questions: The assessment of participant's practice on ADR reporting included seven questions (items) on experience of ADRs, report to pharmacovigilance centre, ADR reporting form, training to report ADRs, reporting of serious adverse event, identification of rare ADRs, methods 
to monitor ADRs of new drug, presence of Pharmacovigilance Committee in Institute.

\section{Data collection}

All the Doctors who were available at the time of the survey were approached personally by the principal investigator. The subjects were asked to respond to each item according to the response format provided in the questionnaire. Response format included multiple choice questions in which the subjects were asked to choose an appropriate response from provided list of options. The investigator recorded the responses of the doctors in the printed format. The completed response format was carefully checked by the investigator.

A total of hundred and ten questionnaires (110) were distributed among the doctors in the morning. Questionnaires were collected by the evening of the same day.

\section{Statistical analysis}

All the obtained data were entered into a personal computer on Microsoft Excel Sheet and analyzed. The variables were characterized by their counts, percentages and frequencies.

\section{RESULTS}

A total of 110 questionnaires were distributed, all of them were returned back and were analyzed, giving a response rate of $100 \%$.

The most of the respondents were males, that is, $60 \%$ compared to $40 \%$ females. Furthermore, the mean age of the study participants was 35.85 years.

While assessing the knowledge of the doctors on pharmacovigilance, it was found that a highest of $74.07 \%$ medical professionals gave correct response regarding the definition of pharmacovigilance. According to $67.31 \%$ responders the most important purpose of pharmacovigilance is to identify a safety of the drug. As many $69.23 \%$ doctors believed that ADR reporting is a professional obligation for them. Majority of the responders $88.89 \%$, were aware that ADRs can also be reported by nurses and pharmacists respectively. Similarly, $65.45 \%$ doctors were aware regarding the existence of National Pharmacovigilance Programme (NPP). Furthermore, that is, $44.44 \%$ responders had knowledge of location of international ADR monitoring center while $79.59 \%$ prescribers were aware that the regulatory body responsible for monitoring ADRs in India is Central Drugs Standard Control Organization (CDSCO). Only $22.45 \%$ of responders knew about the existence of a Pharmacovigilance center or ADR Monitoring Center (AMC) in their college. Also 51.06\% doctors were aware about the phase of clinical trial in which rare adverse effects were commonly found.
Table 1: Assessment of pharmacovigilance related knowledge.

\begin{tabular}{|lll|}
\hline Concept question & $\begin{array}{l}\text { Correct } \\
\text { answer }\end{array}$ & $\begin{array}{l}\% \\
\text { Responders }\end{array}$ \\
\hline & $\begin{array}{l}\text { Detection, } \\
\text { Assessment, }\end{array}$ \\
$\begin{array}{l}\text { Pharmacovigilance } \\
\text { Definition }\end{array}$ & $\begin{array}{l}\text { Understandi } \\
\text { ng and } \\
\text { prevention } \\
\text { of adverse } \\
\text { effects }\end{array}$ & 74.07 \\
\hline $\begin{array}{l}\text { Purpose of } \\
\text { Pharmacovigilance }\end{array}$ & $\begin{array}{l}\text { To identify } \\
\text { safety of the }\end{array}$ & 67.31 \\
\hline $\begin{array}{l}\text { ADR reporting is } \\
\text { professional obligation }\end{array}$ & Yes & 69.23 \\
\hline $\begin{array}{l}\text { Responsible for } \\
\text { reporting ADR }\end{array}$ & $\begin{array}{l}\text { All the } \\
\text { above }\end{array}$ & 88.89 \\
\hline Existence of NPP India & Yes & 65.45 \\
\hline Monitoring ADRs & CDSCO & 79.59 \\
\hline $\begin{array}{l}\text { Your institution has an } \\
\text { ADR monitoring } \\
\text { Centre }\end{array}$ & Yes & 22.45 \\
\hline $\begin{array}{l}\text { International centre for } \\
\text { adverse drug reaction }\end{array}$ & Sweden & 44.44 \\
\hline $\begin{array}{l}\text { Rare ADRs can be } \\
\text { identified in the } \\
\text { following phase of a } \\
\text { clinical trial }\end{array}$ & $\begin{array}{l}\text { During } \\
\text { phase-4 } \\
\text { clinical trials }\end{array}$ & 51.06 \\
\hline $\begin{array}{l}\text { Where is the nearest } \\
\text { sub zonal centre for } \\
\text { ADR monitoring } \\
\text { located }\end{array}$ & Bangalore \\
\hline
\end{tabular}

While assessing the pharmacovigilance related attitude of the doctors, it was found that a total of $98.15 \%$ responders agreed that reporting of ADR is necessary. Overall, $94.44 \%$ doctors, were of the view that pharmacovigilance should be taught in detail to health-care professionals. In continuation with this, only few, that is, $55.56 \%$ responders have read articles on prevention of ADRs. Furthermore, $71.70 \%$ doctors felt that ADR monitoring center should be established in every hospital. $40.43 \%$, $31.91 \%, 19.15 \%$, and $8.51 \%$ of responders respectively cited Difficult to decide whether ADR has occurred or not, Lack of time to report ADR, A single unreported case may not affect ADR database and No remuneration to be the possible causes of under reporting of ADRs.

On assessing the pharmacovigilance-related practices, it was found that $80 \%$ of doctors have experienced ADRs in patient during their practice. But, very few of them, that is, $25.45 \%$ have ever reported ADR to pharmacovigilance center. Furthermore, it was observed that only $29.09 \%$ medical professionals have ever seen the ADR reporting form. 
In accordance with this, it was found that only $16.36 \%$ medical professionals have been trained on reporting on ADR. In addition, only $35.19 \%$ doctors agreed that there is a Pharmacovigilance Committee in their Institution.

Table 2: Assessment of pharmacovigilancerelated attitude.

\begin{tabular}{|c|c|c|}
\hline Concept question & $\begin{array}{l}\text { Correct } \\
\text { answer }\end{array}$ & $\begin{array}{l}\text { \% } \\
\text { Responders }\end{array}$ \\
\hline $\begin{array}{l}\text { Reporting of adverse drug } \\
\text { reaction is necessary }\end{array}$ & Yes & 98.15 \\
\hline $\begin{array}{l}\text { Pharmacovigilance to be } \\
\text { taught in detail to } \\
\text { healthcare professionals }\end{array}$ & Yes & 94.44 \\
\hline $\begin{array}{l}\text { Article on prevention of } \\
\text { adverse drug reactions }\end{array}$ & Yes & 55.56 \\
\hline $\begin{array}{l}\text { Establishing ADR } \\
\text { monitoring center }\end{array}$ & $\begin{array}{l}\text { Should be in } \\
\text { every hospital }\end{array}$ & 71.70 \\
\hline \multirow{4}{*}{$\begin{array}{l}\text { Factors discouraging } \\
\text { reporting of ADRs }\end{array}$} & $\begin{array}{l}\text { Difficult to } \\
\text { decide whether } \\
\text { ADR has } \\
\text { occurred or not }\end{array}$ & 40.43 \\
\hline & $\begin{array}{l}\text { Lack of time to } \\
\text { report ADR }\end{array}$ & 31.91 \\
\hline & $\begin{array}{l}\text { A single } \\
\text { unreported case } \\
\text { may not affect } \\
\text { ADR database }\end{array}$ & 19.15 \\
\hline & $\begin{array}{l}\text { No } \\
\text { remuneration }\end{array}$ & 8.51 \\
\hline
\end{tabular}

Table 3: Assessment of pharmacovigilancerelated practices.

\begin{tabular}{|lll|}
\hline $\begin{array}{l}\text { Concept question } \\
\begin{array}{l}\text { Experienced adverse } \\
\text { drug reactions }\end{array}\end{array}$ & $\begin{array}{l}\text { Correct } \\
\text { answer }\end{array}$ & $\begin{array}{l}\% \\
\text { Responders }\end{array}$ \\
\hline $\begin{array}{l}\text { Reported ADR to } \\
\text { centre }\end{array}$ & Yes & 80.0 \\
\hline ADR reporting form & Yes & 29.45 \\
\hline Trained to report ADR & Yes & 16.36 \\
\hline $\begin{array}{l}\text { Pharmacovigilance } \\
\text { committee in your } \\
\text { Institute }\end{array}$ & Yes & 35.19 \\
\hline $\begin{array}{l}\text { Methods commonly } \\
\text { employed by the } \\
\text { healthcare professional } \\
\text { to monitor adverse } \\
\text { drug reactions of new } \\
\text { drugs }\end{array}$ & $\begin{array}{l}\text { Spontaneous } \\
\text { reporting } \\
\text { system }\end{array}$ & 31.91 \\
\hline $\begin{array}{l}\text { How do you report } \\
\text { ADR }\end{array}$ & $\begin{array}{l}\text { Filled ADR } \\
\text { form } \\
\text { submitted to } \\
\text { pharmacovig } \\
\text { ilance centre }\end{array}$ & \\
\hline
\end{tabular}

\section{DISCUSSION}

ADR reporting is an integral part of pharmacovigilance and is important for patient care. Underreporting of ADR is a major threat to the success of pharmacovigilance program.

The ultimate aim of pharmacovigilance is to ensure safe and rational use of medicine. The most important outcome of pharmacovigilance is the prevention of patients being affected unnecessarily by the negative consequences of pharmacotherapy. ${ }^{13,14}$

The purpose of this study was mainly to assess the knowledge, attitude and practice of pharmacovigilance among the prescribers and to find out the reason for under reporting if any. It was anticipated that this study would help to identify the causes of under reporting of ADR and accordingly a proper intervention can be planned based on the results of study.

Most of the doctors (98.15\%) accepted that reporting ADR is necessary, and $94.44 \%$ agreed that pharmacovigilance should be taught in detail to health-care givers. These findings are in correlation with findings of a study conducted by Gupta SK, et al. ${ }^{12}$

Majority $65.45 \%$ doctors knew the existence of NPP. Also, that is, $79.59 \%$ doctors knew that in India the CDSCO is a regulatory body responsible for monitoring ADRs. These findings are similar compared to other studies conducted among the health-care providers. ${ }^{12}$

According to the outcomes of our research, doctors practice toward ADR reporting was far below expectation. We observed that there was a huge gap between the ADR experienced $(80 \%)$, and ADR reported $(25.45 \%)$ by the health-care providers. These findings are similar to those reported by other studies conducted in other countries like Malaysia, Portugal and Nigeria. ${ }^{15-17}$

The factors responsible for underreporting were also determined in this study. The determinants of underreporting, from our study include no remuneration, lack of time to report ADR, belief that a single unreported case may not affect ADR database, and difficulty to decide whether ADR has occurred or not. Other reasons were lack of training, unawareness regarding the ADR reporting form, ignorance of the rules, and procedure for reporting.

It was noticed that the participants in our study could not utilize their knowledge to conduct proper ADR reporting since they had a lack of training in this regard. We found that only $16.36 \%$ health-care providers were trained on how to report ADR. Similarly, a survey conducted in United Arab Emirates revealed that only 5.5\% of doctors received training on ADR reporting. ${ }^{18}$ 
This shows that there is an urgent need for all stakeholders to come together to ensure proper implementation of pharmacovigilance program.

Nwokikein in his study suggested that attention should shift from spontaneous reporting by health-care workers to self-report or patient initiated reporting of ADRs; encouraging health-care professionals to self-report incidences of personal experiences of ADR may motivate them into engaging in pharmacovigilance activities after graduation. ${ }^{19}$

Many Indian studies have indicated that there is a gradual increase in the knowledge and attitude of the health-care professionals toward pharmacovigilance but unfortunately, it seems that the actual practice of ADR reporting is still deficient. . $^{8,11,20,21}$

It has been reemphasized that there is a positive correlation between training of Pharmacovigilance and reporting ADR by health-care professionals. ${ }^{11}$ Factors like unawareness about the method to decide the causal relationship between the ADR can only be removed by regular training. ${ }^{16}$

The significance of adverse event monitoring and reporting can be increased through academic interference. This will ultimately help in improving the efficiency of pharmacovigilance program in India.

Authors recommend that hospital managements, pharmaceutical companies, drug regulatory agencies should play a significant role toward educating doctors on ADR monitoring and reporting.

\section{Limitations}

Limitations of the study include; results are of only a single teaching hospital and those inherent to questionnairebased studies such as subjective response and recall bias. It would be logical to extend this study to other teaching hospitals, private practitioners, members of allied fields, students of medical and associated streams to enable us generalize our findings.

\section{CONCLUSION}

The results of our study indicate that the majority of the doctors had a good knowledge and attitude about pharmacovigilance. But there was a huge gap between the ADR experienced, and ADR reported by the health-care givers. Similarly, a clear-cut correlation between training of pharmacovigilance and reporting ADR was found. Furthermore, the majority of the respondents agreed that reporting of ADR is necessary and awareness that pharmacovigilance should be taught in detail to the healthcare professionals. It has been advised that the health-care professionals; especially dental and nursing should be trained properly on ADR reporting to improve the current scenario in the pharmacovigilance program of the country.

\section{ACKNOWLEDGEMENTS}

Authors would like to thank Mr. Narayanaswamy D.M, statistician in Shridevi Institute of Medical Sciences and Research Hospital for his contribution in analyzing the data. Also thank all the doctors of Shridevi Institute of Medical Sciences and Research Hospital, Tumkur, Karnataka, India, who have participated in this study.

Funding: No funding sources

Conflict of interest: None declared

Ethical approval: The study was approved by the Institutional Ethics Committee of Shridevi Institute of Medical Sciences \& Research Hospital, Tumkur

\section{REFERENCES}

1. Meher BR, Joshua N, Asha B, Mukherji D. A questionnaire based study to assess knowledge, attitude and practice of Pharmacovigilance among undergraduate medical students in a Tertiary Care Teaching Hospital of South India. Perspect Clin Res. 2015;6:217-21.

2. Reddy VL, Pasha SKJ, Rathinavelu M, Reddy YP. Assessment of knowledge, attitude and perception of Pharmacovigilance and Adverse Drug Reaction (ADR) reporting among the Pharmacy students in South India. JPBS. 2014;9(2):34-43.

3. Classen DC, Pestotnik SL, Evans RS, Lloyd JF, Burke JP. Adverse drug events in hospitalized patients: Excess length of stay, extra costs, and attributable mortality. JAMA. 1997;277(4):301-6.

4. Rodriguez MR, Otero MJ, Rovira J. Assessing the economic impact of adverse drug effects. Pharmacoeconomics. 2003;21(9):623-50.

5. Lee A, Thomas SHL. Adverse drug reactions In: Walker $\mathrm{R}$ and Edward C. Clinical pharmacy and Therapeutics. $3^{\text {rd }}$ Edition, Churchill Livingstone; 2003:33-46.

6. Safety of medicines: A guide to detecting and reporting adverse drug reactions. World Health Organization, Geneva, 2002. Available at: http://apps.who.int/medicinedocs/en/d/Jh2992e/ [Accessed May 12, 2017]

7. Feely J, Moriarty S, O' Connor P. Stimulating reporting of adverse drug reaction by using a fee. $\mathrm{Br}$ Med J. 1990;300:22-3.

8. Khan SA, Goyal C, Chandel N, Rafi M. Knowledge, attitude and practice of doctors to adverse drug reaction reporting in a teaching hospital in India: An observational study. Journal of Natural Science, Biology and Medicine. 2013;4(1):191- 6.

9. Radhakrishnan R, Sudha V, Varma DM. An Educational Intervention to assess Knowledge Attitude Practice of pharmacovigilance among Health care professionals in an Indian tertiary care teaching hospital. International Journal of Pharm Tech Research CODEN (USA): IJPRIF. April-June 2011;3(2):678-92. 
10. Desai CK, Iyer G, Panchal J, Shah S, Dikshit RK. An evaluation of Knowledge, Attitude and Practice of Pharmacovigilance among the Prescribers at a Tertiary care Hospital. Perspect Clin Res. 2011;2(4):129-36.

11. Hardeep, Bajaj JK, Rakesh K. A Survey on the Knowledge, Attitude and the Practice of Pharmacovigilance Among the Health Care Professionals in a Teaching Hospital in Northern India. Journal of Clinical and Diagnostic Research. 2013;7:97-9.

12. Gupta SK, Nayak RP, Shivaranjani R, Vidyarthi SK. A questionnaire study on the knowledge, attitude, and the practice of pharmacovigilance among the healthcare professionals in a teaching hospital in South India. Perspect Clin Res. 2015;6:45-52.

13. Kulkarni MD, Baig MS, Chandaliya KC, Doifode SM, Razvi SU, Sindhu NS. Knowledge attitude and practice of pharmacovigilance among prescribers of government medical college and hospital, Arungabad (Maharastra). International journal of pharmacology and therapeutics. 2013;3(3):10-8.

14. Palaian S, Ibrahim MI, Mishra P. Health Professional's knowledge, attitude and practices towards pharmacovigilance in Nepal. Pharmacy Practice. 2011;9(4):228-35.

15. Aziz Z, Siang TC, Badarudin NS. Reporting of adverse drug reactions: Predictors of under-reporting in Malaysia. Pharmacoepidemiol Drug Saf. 2007;16:223-8.

16. Herdeiro MT, Figueiras A, Polónia J, Gestal-Otero JJ. Physicians' attitudes and adverse drug reaction reporting: A case-control study in Portugal. Drug Saf. 2005;28:825-33.

17. Okezie EO, Olufunmilayo F. Adverse drug reactions reporting by physicians in Ibadan, Nigeria. Pharmacoepidemiol Drug Saf. 2008;17:517-22.

18. John LJ, Arifulla M, Cheriathu J, Sreedharan J. Reporting of adverse drug reactions: A study among clinicians. J Appl Pharm Sci. 2012;2:135-9.

19. Nwokike J. Monitoring Adverse Drug Reaction in the Public Health Programs: The Case of the Nigeria TB Program; 2008. Available at: http://www.apps.who.int/medicinedocs/documents/s1 8400en/ s18400en.pdf. [Last accessed on 2017 June $10]$.

20. Muraraiah S, Rajarathna K, Sreedhar D, Basavalingu D, Jayanthi CR. A questionnaire study to assess the knowledge, attitude and practice of pharmacovigilance in a paediatric tertiary care centre. J Chem Pharm Res. 2011;3:416-22.

21. Remesh A. Identifying the reasons for under reporting of ADR: A cross sectional survey. Res J Pharm Biol Chem Sci. 2012;3:1379-86.

Cite this article as: Shivarudraiah PR, Kudthni RH, Ramakrishna S, Koushik SS, Karki PV, Kedia R. An evaluation of knowledge, attitude and practice of pharmacovigilance among prescribers in a teaching hospital of south India. Int J Basic Clin Pharmacol 2017;6:2265-70. 